\title{
Dose-escalated robotic SBRT for stage I-II prostate cancer
}

\author{
Robert Meier * \\ Swedish Radiosurgery Center, Seattle, WA, USA
}

\section{Edited by:}

Alan Jay Katz, Flushing Radiation

Oncology, USA

\section{Reviewed by:}

Alan Dal Pra, Bern University

Hospital, Switzerland

Alan Jay Katz, Flushing Radiation

Oncology, USA

${ }^{*}$ Correspondence:

Robert Meier, Swedish Radiosurgery

Center, 550 17th Avenue, Suite A10,

Seattle, WA 98122, USA

e-mail: robert.meier@swedish.org

\begin{abstract}
Stereotactic body radiotherapy (SBRT) is the precise external delivery of very high-dose radiotherapy to targets in the body, with treatment completed in one to five fractions. SBRT should be an ideal approach for organ-confined prostate cancer because (I) dose-escalation should yield improved rates of cancer control; (II) the unique radiobiology of prostate cancer favors hypofractionation; and (III) the conformal nature of SBRT minimizes high-dose radiation delivery to immediately adjacent organs, potentially reducing complications. This approach is also more convenient for patients, and is cheaper than intensity-modulated radiotherapy (IMRT). Several external beam platforms are capable of delivering SBRT for early-stage prostate cancer, although most of the mature reported series have employed a robotic non-coplanar platform (i.e., CyberKnife). Several large studies report 5-year biochemical relapse rates which compare favorably to IMRT. Rates of late GU toxicity are similar to those seen with IMRT, and rates of late rectal toxicity may be less than with IMRT and low-dose rate brachytherapy. Patient-reported quality of life (QOL) outcomes appear similar to IMRT in the urinary domain. Bowel QOL may be less adversely affected by SBRT than with other radiation modalities. After 5 years of follow-up, SBRT delivered on a robotic platform is yielding outcomes at least as favorable as IMRT, and may be considered appropriate therapy for stage I-II prostate cancer.
\end{abstract}

Keywords: prostate cancer, stereotactic body radiotherapy, hypofractionation

\section{BACKGROUND}

Prostate cancer is the most common malignancy in men. An estimated 233,000 cases will be diagnosed in the United States in 2014 (1). PSA screening has led to earlier stage diagnoses; in 1998, 92\% of prostate cancers were diagnosed with clinically organ-confined disease (2). Based on pre-treatment prognostic parameters, several systems have been proposed to stratify prostate cancer into differing risk groups; these are summarized in Table 1. In 2010, the seventh edition of the AJCC Staging Manual (3), added Gleason score and PSA to the TNM staging system, making these stage grouping roughly comparable to those of D'Amico and NCCN, with notable differences in the intermediate- and highrisk groups. NCCN also adds "very low-risk" and "very high-risk" categories.

Nearly $50 \%$ of patients (4) diagnosed with prostate cancer fall in prognostic AJCC Stage I, which includes patients with a clinical stage of T1-T2a, PSA $<10$, and Gleason 6. Active surveillance has become a suitable alternative for AJCC stage I, also referred to as "low-risk," patients (5). The PIVOT trial randomized PSA-era diagnosed patients between radical prostatectomy and observation. The study was not designed to compare outcomes in the various risk groups, thus firm conclusions about subgroups cannot be made. Nevertheless, in the PIVOT trial, surgery was associated with 50 and $60 \%$ reductions in prostate cancer deaths for intermediate- and high-risk groups (D'Amico definition), respectively. This bolsters clinicians' recommendations that these groups undergo definitive therapy.

According to the Prostate Cancer Clinical Guideline Panel of the American Urological Association in 2007 (6), treatment options that should be discussed include radical prostatectomy, radiotherapy with or without androgen deprivation, and active surveillance.

\section{HISTORICAL EVOLUTION OF RADIOTHERAPY FOR PROSTATE CANCER}

Radiotherapy was first used to treat prostate cancer in the first half of the twentieth century; the application of radium or kilovoltage therapy yielded disappointing results $(7,8)$. The development of megavoltage external beam platforms in the 1950s (9-11) allowed higher doses to be delivered, with encouraging outcomes. The next important development was CT imaging and computerized treatment planning, which facilitated three-dimension conformal external beam planning and intensity-modulated radiotherapy (IMRT). These more sophisticated treatment plans yielded better dose conformity to the target, allowing further doseescalation. Conformal, dose-escalated techniques have yielded varying disease-free outcomes, approximately similar to those seen with radical prostatectomy (see Table 2), although not without toxicity.

Several randomized trials $(22,27,28)$ have confirmed that dose-escalation yields improved relapse-free survival rates. Fowler's dose-response analysis in intermediate-risk patients (29) (see Figure 1) indicates doses up to around 90 Gy are necessary to minimize recurrence rates. A meta-analysis of seven randomized dose-escalation trials yielded the same conclusion (30). A variety of strategies have been employed to further escalate dose and/or reduce toxicity to surround normal tissues. 


\begin{tabular}{|c|c|c|c|}
\hline Clinical prognostic factors & D’Amico & NCCN & AJCC seventh edition \\
\hline $\begin{array}{l}\text { T1c, PSA }<10 \mathrm{ng} / \mathrm{ml} \text { and PSA density }<0.15 \mathrm{ng} / \mathrm{ml} / \mathrm{g} \text {, Gleason } \leq 6 \text { and } \\
\leq 3 \text { cores positive, and } \leq 50 \% \text { cancer any core }\end{array}$ & Low-risk & Very low-risk & Stage I \\
\hline T1-T2a, PSA $<10$, Gleason $\leq 6$ & Low-risk & Low-risk & Stage I \\
\hline T2b or PSA $10-20$ or Gleason $=7$ (single risk factor) & Intermediate-risk & Intermediate-risk & Stage Ila \\
\hline T2b, PSA $10-20$, Gleason $=7$ ( $\geq 2$ risk factors) & Intermediate-risk & Can shift to high-risk & Stage Ila \\
\hline T2c and/or PSA > 20 and/or Gleason $=8-10$ & High-risk & High-risk & Stage $\| \mathrm{b}$ \\
\hline T3b-T4, any PSA, any Gleason & & Very high-risk & Stage III or IV \\
\hline
\end{tabular}

Table 2 | bDFS outcomes for low-risk prostate cancer.

\begin{tabular}{|c|c|c|c|c|c|c|c|c|}
\hline \multirow[t]{2}{*}{$\mathbf{R x}$} & \multirow[t]{2}{*}{ Institution/author } & \multirow[t]{2}{*}{ Details } & \multirow[t]{2}{*}{ Pts } & \multirow{2}{*}{$\begin{array}{l}\text { Median } \\
\text { F/U years }\end{array}$} & \multicolumn{4}{|c|}{ 5-Year bDFS and definition (\%) } \\
\hline & & & & & Nadir +2 & ASTRO & $\mathrm{PSA} \geq 0.2$ & Average $^{a}$ \\
\hline \multirow[t]{2}{*}{$\mathrm{HDR}+\mathrm{EBRT}$} & Seattle, Kiel, Beaumont (12) & $45-50 \mathrm{~Gy}+2-4 \mathrm{fx}$ boost & 46 & 5 & & 96 & & 92 \\
\hline & CA endocurietherapy (13) & $36 \mathrm{~Gy}+5.5-6 \mathrm{~Gy} \times 4$ boost & 70 & 7.25 & 93 & 90 & & \\
\hline \multirow[t]{2}{*}{ LDR } & RTOG 9805 (16) phase II & 145 Gy I-125 alone & 95 & 5.3 & 99 & 93 & & 88 \\
\hline & 11 Inst meta-analysis (17) & $\mathrm{I}-125$ and $\mathrm{Pd}-103$ alone & 1,444 & 5.25 & 86 & 88 & & \\
\hline \multirow[t]{3}{*}{ External beam } & Clev Clin (18) hypofract & IMRT: $70 \mathrm{~Gy}, 2.5 \mathrm{~Gy} / \mathrm{fx}$ & 36 & 5.5 & 97 & 97 & & 88 \\
\hline & MSKCC (19) & IMRT: $81 \mathrm{~Gy}, 1.8 \mathrm{~Gy} / \mathrm{fx}$ & 203 & 7 & 93 & 85 & & \\
\hline & 9 Instit meta-analysis (20) & 3-D RT/IMRT: > 72 Gy & 70 & 5.7 & & 79 & & \\
\hline \multirow[t]{4}{*}{ Radic prost } & Baylor: Hull (23) & & 299 & 3.9 & & & $92.5^{d}$ & 94 \\
\hline & Clev Clin, MSK: Kupelian (24) & & 524 & 5.5 & & & 92 & \\
\hline & Univ Penn: D'Amico (25) & & 322 & 5 & & 88 & & \\
\hline & Johns Hopkins: Han (26) & & 899 & 5.9 & & & 98 & \\
\hline
\end{tabular}

bDFS estimated based on proportions within each risk group.

a Weighted average of ASTRO bDFS or of stated bDFS definition in prostatectomy series.

${ }^{b} 75 \%$ low-risk, $25 \%$ intermediate.

Included T2b in low-risk group.

aPSA $\geq 0.4$.

bDFS, biochemical disease-free survival; EBRT, external beam radiotherapy; IMRT, intensity-modulated radiotherapy; LDR, low-dose rate brachytherapy; HDR, High-dose rate brachytherapy.

Modern radiotherapy plans still had to account for variations in patient positioning, inaccuracies in treatment delivery, and internal organ motion. Radiation oncologists account for these uncertainties by adding a radial margin around the intended target, creating a "planning target volume (PTV)." This expanded target extends the high-dose treatment region into the surrounding normal structures. A PTV expansion of about $1 \mathrm{~cm}$ is required when skin marks are used for positioning. Set-up uncertainty can be reduced by placing gold fiducials in the prostate and imaging prior to treatment delivery. This does not account for movement within a given treatment session, or "intra-fractional" motion.
Kupelian (31) demonstrated that in 15\% of treatment sessions, the prostate moved more than $5 \mathrm{~mm}$. A study from the Mayo Clinic (32) recommended a 5-mm margin to account for intra-fractional motion. The expanded PTV required in IMRT employing pretreatment image guidance has limited the maximum safe dose around $82 \mathrm{~Gy}$, if delivered at $2 \mathrm{~Gy}$ per fraction.

Proton therapy offers the prospect of prostate dose-escalation while limiting exposure to normal tissues. Proton beams deposit radiation until after passing beyond the target, where the dose then falls off rapidly. This reduces the radiation dose to normal tissues, potentially yielding fewer side effects. However, like IMRT, 


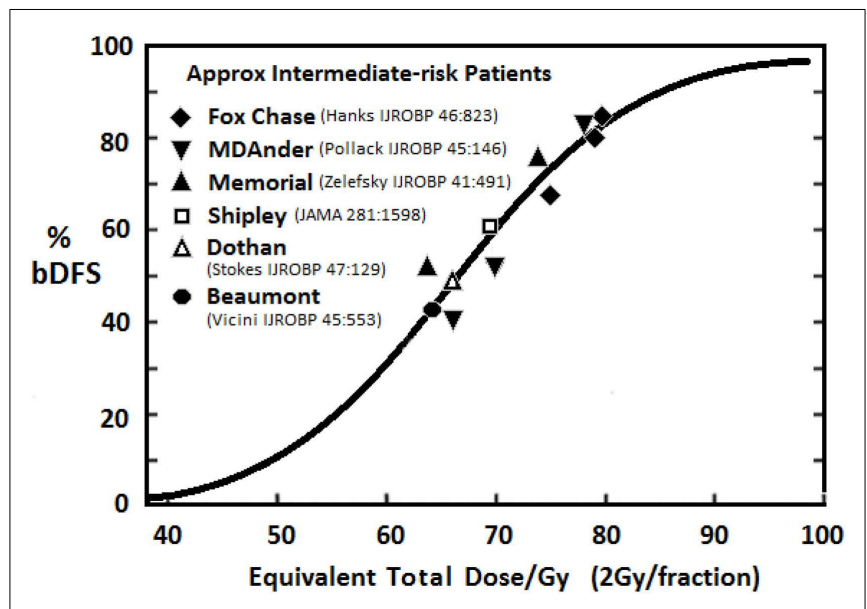

FIGURE 1 | Relationship between dose and 5-year freedom from PSA failure for intermediate-risk patients treated with EBRT [adapted from Fowler (29)]

proton beam plans must account for prostate motion, thus the same large PTVs must be targeted. Also, since most proton beam plans employ only two beams, conformal dose sculpting around the prostate is not possible. While proton therapy reduces the volume of normal tissues receiving low dose radiation, large volumes of the rectum still receive high-dose radiation. In one study (33), protons yielded a $50 \%$ greater incidence of rectal toxicity compared to IMRT. The American College of Radiology Study (03-12) demonstrated (34) significant (8\%) late grade $3+$ rectal toxicity when proton dose was escalated to $82 \mathrm{~Gy}$. Proton dose-escalation beyond $82 \mathrm{~Gy}$ is thus not possible with current technology, and long-term GI toxicity appears to be no better, and perhaps inferior to IMRT.

Transperineal ultrasound-guided brachytherapy allows the delivery of conformal, high-dose radiotherapy to the prostate, with a rapid dose fall-off outside of the implanted region. In low-dose rate (LDR) implants, 70-100 iodine-125 (I-125) or palladium103 (Pd-103) sources are permanently placed within the prostate; these "seeds" slowly deliver radiation over the ensuing 2-6 months. For patients with low-risk prostate cancer, a single LDR implant (monotherapy) yields favorable long-term outcomes (35-37). Patients with intermediate- or high-risk disease usually require a 5-week course of external beam radiotherapy plus the LDR implant $(38,39)$. When post-implant dosimetry demonstrates that the prostate received a biologically equivalent dose (BED) of around $200 \mathrm{~Gy}$, LDR brachytherapy yields exceptionally high relapse-free survival rates (40). This is equivalent to about $110 \mathrm{~Gy}$ at $2 \mathrm{~Gy} / \mathrm{fx}$, assuming $\alpha / \beta=1.5$. Unfortunately, toxicity following LDR brachytherapy appears to be greater than IMRT. Fox-Chase (41) reported 3-year grade 2+ GI and GU toxicities rates were three and fivefold greater following seed implants. Sanda's patientreported quality of life (QOL) study (42) did not directly compare treatments, however greater declines in urinary and bowel scores were observed following brachytherapy than after external beam radiotherapy.

\section{HYPOFRACTIONATION}

High-dose rate (HDR) brachytherapy has been used in the treatment of prostate cancer since the 1980s (43-50). Catheters are placed temporarily in the prostate, and then loaded with a highdose Iridium-192 source, delivering a few fractions of very highdose RT. Initial protocols employing HDR combined conventionally fractionated external beam RT with an HDR boost. More recent reports have employed HDR as monotherapy (14, 15, $45,51-53)$. Adjusting for pre-treatment risk factors, these studies yield biochemical disease-free survival (bDFS) outcomes at least as favorable to those seen with LDR brachytherapy or conformal dose-escalated RT or IMRT (see Table 2). A prospective study from William Beaumont Hospital (15) comparing HDR monotherapy vs. LDR brachytherapy (Pd-103) showed a superior 5-year event-free survival ( 98 vs. $85 \%, P=0.01$ ) and a trend toward improved freedom from cancer failure (98 vs. $92 \%$, $P=0.1)$ in the HDR cohort. The same group showed toxicity and QOL following HDR brachytherapy was more favorable than either LDR brachytherapy or conformal external beam RT (51, 54). These results suggest prostate cancer favorably responds to hypofractionated regimens.

Radiation oncologists fractionate RT dose to reduce toxicity to surrounding normal tissues. For most cancers, by delivering dose over several weeks, equivalent cancer-killing effect is achieved with reduced long-term toxicity. The effect of dose fractionation on both cancer and normal tissues can be estimated using the "linear-quadratic model." In this model, the alpha-beta ratio reflects the response of normal tissues or cancers to changes in RT dose per fraction. Most cancers respond to RT as do rapidly dividing normal tissues (e.g., skin or mucous membranes), and thus have high $\alpha / \beta$ ratios, in the $8-12$ Gy range (55). Tissues with lower $\alpha / \beta$ ratios are more sensitive to large dose per fraction (also known as hypofractionated) RT.

The results of HDR and other hypofractionated regimens led radiobiologists to reconsider $\alpha / \beta$ ratio of prostate carcinoma. Numerous studies have concluded that prostate cancer has an unusually low/ratio of about $1.5 \mathrm{~Gy}(29,56-59)$. A pooled analysis (60) of 5,093 patients yielded a $\alpha / \beta$ ratio of $1.55 \mathrm{~Gy}$. A low $\alpha / \beta$ ratio is consistent with other biologic properties of prostate cancer: an unusually long tumor doubling times (61), and a very low proportion of proliferating cells (62). If the $\alpha / \beta$ ratio for prostate cancer is smaller than the $\alpha / \beta$ ratios for late effects in the surrounding normal tissues $(3-5 \mathrm{~Gy})$, then a therapeutic gain could be achieved by hypofractionation. In this setting, larger doses per fraction should result in equivalent or improved cancer control with reduced toxicity (63-65).

Several prospective clinical trials have evaluated the efficacy of hypofractionated radiotherapy in organ-confined prostate cancer. A large prospective study from the Cleveland Clinic (66) demonstrated favorable relapse-free survival and low toxicity with $70 \mathrm{~Gy}$ given in 2.5 Gy fractions. A trial from Royal Adelaide Hospital in Australia (67) randomized 217 patients between $64 \mathrm{~Gy}$ in $2 \mathrm{~Gy} / \mathrm{fx}$ vs. $55 \mathrm{~Gy}$ in $2.75 \mathrm{~Gy} / \mathrm{fx}$; these schedules are isoeffective if prostate $\alpha / \beta=2.5$. The hypofractionated arm showed a significantly better bDFS (53 vs. $43 \%$ ), with equal toxicity in the two arms. In an Italian trial (68), 168 high-risk patients were randomized 
between $62 \mathrm{~Gy}$ in $3.1 \mathrm{~Gy} / \mathrm{fx}$ vs. $80 \mathrm{~Gy}$ in $2 \mathrm{~Gy} / \mathrm{fx}$ (isoeffective if prostate $\alpha / \beta=1.8$; both arms received 9 months of androgen ablation). Toxicities were equal. Overall relapse rates were equivalent, although improved cancer control was suggested if presenting PSA was 20 or less. Thus, the radiobiologic assertion that the $\alpha / \beta$ ratio for prostate cancer is low (1.5-1.8) has been confirmed by class 1 evidence.

Stereotactic body radiotherapy (SBRT) is the precise external delivery of very high-dose radiotherapy to targets in the body, with treatment completed in one to five fractions. Dose conformality is achieved using cross-firing ionizing radiation beams and imageguidance. By concentrating dose in the targeted cancer, SBRT maximizes cell-killing. Rapid dose fall-off minimizes radiationrelated injury to adjacent normal tissues. Organ-confined prostate cancer should be ideally suited for SBRT as (I) dose-escalation should yield better outcomes; (II) the toxicity from treatment is due to high-dose radiation exposure to the organs immediately adjacent to the prostate; and (III) the unique radiobiology of prostate cancer favors hypofractionation.

\section{SBRT PLATFORMS}

Several external beam platforms can theoretically deliver stereotactic radiotherapy for prostate cancer. Table 3 summaries the capability of these devices. At a minimum, target localization prior to daily treatments is required. This can be performed using X-ray imaging of implanted fiducials, or on-board CT imaging. If intrafractional image guidance is not employed, then at least $5 \mathrm{~mm}$ PTV expansions are required to account for target motion. If the target can be localized during treatment, then smaller PTV expansions can be employed, potentially reducing dose to surrounding organs. The accuracy of different real-time localization systems can vary considerably. For example, with the Novalis or Varian TrueBeam systems, typically localization and target positioning occurs only once prior to each treatment. With the Calypso system, the operator sets a threshold (typically 3-5 mm) beyond which treatment is interrupted and the patient positioning corrected. With the CyberKnife, continuous image acquisition and target correction occurs routinely; the Stanford group showed that when intra-fractional correction is done every $40 \mathrm{~s}$, this device achieves sub-millimeter accuracy (69).

Correction for target motion must account for translational (i.e., anterior/posterior, right/left, and superior/inferior) motion. Since rotational motion, particularly pitch, can be substantial, correction for rotations may be beneficial, although this potential benefit has not been quantified. The use of multiple non-coplanar beams should yield better dose conformality than single-plane treatments. While non-coplanar delivery is possible for any platform, in practice, centers employing gantry-based linacs treat in a coplanar fashion, as non-coplanar delivery adds complexity and time. The intrinsically non-coplanar CyberKnife platform is reported (70) to yield more conformal treatment plans than IMRT.

\section{CLINICAL SBRT OUTCOMES}

The first report (71) of hypofractionated stereotactic radiotherapy treated 40 low-risk patients using a conventional linear accelerator with daily localization of implanted fiducials. 33.5 Gy was delivered in five fractions to the prostate plus a $4-5-\mathrm{mm}$ margin. Toxicities were acceptable. Four-year nadir +2 bDFS was $90 \%$, suggesting further dose-escalation would be beneficial.

The feasibility of SBRT employing further dose-escalation was first reported by King at Stanford University (72) using the CyberKnife platform. 36.25 Gy in five fractions of 7.25 Gy was delivered to the prostate plus a 3-5-mm margin. In the most recent update (73) of long-term outcomes in 67 patients, there were no grade $4+$ toxicities. Two patients had a grade 3 urinary toxicity, and there were no grade 3 GI toxicities. Toxicities compared favorably to other radiation modalities. Five-year Kaplan-Meier PSA relapse-free survival was $94 \%$. The majority of subsequent reports of prostate SBRT have employed the same platform. In a series of 304 patients treated with CyberKnife at Winthrop hospital, 5-year bDFS was 97, 90.7, and 74.1\% in low-, intermediate-, and high-risk groups, respectively. Five grade 3 complications were reported, all $\mathrm{GU}$, for an incidence rate of $2 \%$. In a pooled analysis of eight institutions (74), 1,100 patients were treated with CyberKnife SBRT and followed a median of 36 months. Five-year

Table 3 | SBRT platforms.

\begin{tabular}{|c|c|c|c|c|}
\hline Platform & Description & Target localization method & Real-time correction & $\begin{array}{l}\text { Rotational } \\
\text { correction }\end{array}$ \\
\hline CyberKnife & $\begin{array}{l}\text { Linac on robotic arm, non-coplanar } \\
\text { delivery, variable aperture or multileaf }\end{array}$ & $\begin{array}{l}\text { Orthogonal X-rays, image } \\
\text { implanted fiducials }\end{array}$ & $\begin{array}{l}\text { Continuous, automated } \\
\text { sub-millimeter correction }\end{array}$ & $\begin{array}{l}\text { Yes, continuous } \\
\text { automatic }\end{array}$ \\
\hline $\begin{array}{l}\text { Varian (Trilogy, TrueBeam } \\
\text { etc.), w/Novalis, BrainLab }\end{array}$ & $\begin{array}{l}\text { Linac on gantry. Multileaf collimator. } \\
\text { Volumetric arc therapy available }\end{array}$ & $\begin{array}{l}\text { Cone-beam CT, orthogonal } \\
\text { X-rays, image implanted fiducials }\end{array}$ & $\begin{array}{l}\text { Intermittent; tx interruption } \\
\text { and manual correction }\end{array}$ & $\begin{array}{l}\text { 6-D couch } \\
\text { available }\end{array}$ \\
\hline $\begin{array}{l}\text { Electa (Synergy, VersaHD } \\
\text { etc.) }\end{array}$ & $\begin{array}{l}\text { Linac on gantry. Multileaf collimator. } \\
\text { Volumetric arc therapy available }\end{array}$ & Cone-beam CT & No & $\begin{array}{l}\text { 6-D couch } \\
\text { available }\end{array}$ \\
\hline Calypso & Used with gantry-based linacs & $\begin{array}{l}\text { Implanted beacons provide } \\
\text { real-time localization }\end{array}$ & $\begin{array}{l}\text { Continuous; tx interruption } \\
\text { and manual correction }\end{array}$ & No \\
\hline Tomotherapy & $\begin{array}{l}\text { Linac, helical delivery, multileaf } \\
\text { collimator }\end{array}$ & Megavoltage CT & No & No \\
\hline
\end{tabular}


Table 4 | Prostate SBRT series with mature follow-up.

\begin{tabular}{|c|c|c|c|c|c|c|}
\hline Institution & Platform & $\begin{array}{l}\text { Dose } \\
\text { fractionation }\end{array}$ & $\begin{array}{l}\text { Median } \\
\text { F/U years }\end{array}$ & Risk group & Pts & $\begin{array}{l}\text { 5-Year } \\
\text { bDFS }^{\text {a }}(\%)\end{array}$ \\
\hline Virginia Mason (71) & Gantry-based linac & $6.7 \mathrm{~Gy} \times 5$ & 3.4 & Low & 40 & $90^{\mathrm{b}}$ \\
\hline Stanford (73) & CyberKnife & $7.25 \mathrm{~Gy} \times 5$ & 2.7 & Low and low-intermediate & 67 & 94 \\
\hline Stanford, Naples (79) & CyberKnife & $7-7.25$ Gy × 5 & 5 & Low and low-intermediate & 41 & 93 \\
\hline \multirow[t]{2}{*}{ Winthrop Hospital (78) } & CyberKnife & $7-7.25 \mathrm{~Gy} \times 5$ & 6 & Low & 324 & 97 \\
\hline & & & & Intermediate & 153 & 91 \\
\hline San Bortolo (80) & CyberKnife & $7 \mathrm{~Gy} \times 5$ & 3 & Low, intermediate, and high & 100 & 94 \\
\hline \multirow[t]{3}{*}{ Pooled eight institutions (74) } & CyberKnife & $36-40 \mathrm{~Gy}$ in $4-5 \mathrm{fxs}$ & 3 & Low & 641 & 95 \\
\hline & & & & Intermediate & 334 & 84 \\
\hline & & & & High & 125 & 81 \\
\hline Katz and Kang (81) & CyberKnife & $7-7.25$ Gy × 5 & 5 & High & 97 & 68 \\
\hline Multi-institution (82) & CyberKnife & $8 \mathrm{~Gy} \times 5$ & 3 & Intermediate & 137 & 97 \\
\hline Sunnybrook (76) & Gantry-based linac & $7 \mathrm{~Gy} \times 5$ & 4.75 & Low & 84 & 97 \\
\hline Twenty-first century (77) & Gantry-based linac & $8 \mathrm{~Gy} \times 5$ & 5 & Low & 98 & 99 \\
\hline
\end{tabular}

${ }^{a}$ Nadir +2 definitions.

${ }^{b}$ Four-year bDFS reported.

bDFS, biochemical disease-free survival; SBRT, stereotactic body radiotherapy.

bDFS rates were 95, 84, and 81\% in low-, intermediate-, and highrisk groups, respectively. In a multi-center study (75), CyberKnife treated 129 intermediate-risk prostate cancers 40 Gy in five fractions of $8 \mathrm{~Gy}$ each, with only one grade 3 toxicity reported (GU: bladder injury). More recent reports $(76,77)$ have shown similar favorable outcomes with gantry-based platforms.

The mature series evaluating dose-escalated SBRT are summarized in Table 4. In low-risk patients treated to 35-36.25 Gy in five fractions, 5-year bDFS ranges from 94 to 97\%. In Katz's series (78) of 477 patients with a median follow-up of 6 years, 7-year actuarial relapse-free survival was $95.6 \%$, confirming durable responses. In the low-risk patients treated in the eight-institution pooled analysis (74) and in Katz' series (78), no difference in 5-year bDFS was seen when dose was escalated from 35 to $40 \mathrm{~Gy}$. Sunnybrook (76) demonstrated 97\% 5-year bDFS in 84 low-risk patients treated to $35 \mathrm{~Gy}$ in five fractions with a gantry-based system. In a series (77) of 98 low-risk patients treated to $40 \mathrm{~Gy}$ in five fractions with real-time tracking on a gantry-based linac, only one biochemical failure was reported at 5 years. Current data show no evidence of a dose-response beyond $7 \mathrm{~Gy} \times 5$ in low-risk patients. These SBRT outcomes compare favorably to the 92-97\% 5-year bDFS typically reported with conventionally fractionated external beam radiotherapy (see Table 2 ).

In intermediate-risk patients treated with SBRT, bDFS outcomes vary. In 153 stage IIa patients from Katz's series (78), 7-year bDFS was $90 \%$. In a multi-center study (82) of 137 intermediaterisk patients given $8 \mathrm{~Gy} \times 5$ fractions on the CyberKnife platform, 5 -year bDFS was $96 \%$. In a pooled analysis of eight institutions (74), 5-year bDFS in intermediate-risk patients was only $84 \%$. However, those patients who received biologically higher doses (38 Gy in four fractions or $40 \mathrm{~Gy}$ in five fractions) had 5-year bDFS of $96.7 \%$. The apparent improvement in bDFS in the higher-dose cohort was not statistically significant, and patient populations were not identical. Katz's intermediate-risk group had 1/3 Gleason $4+3$ and excluded patients with two high-risk features, while the multi-institutional study had $20 \%$ Gleason $4+3$ patients, but included some patients with two high-risk features. Longer follow-up and comparisons of larger populations will be necessary to confirm trends suggesting dose-escalation beyond 7.25 Gy $\times 5$ yields better relapse-free survival in intermediate-risk patients. These SBRT 5-year relapse-free survival rates compare favorably to fractionated EBRT $(22,83)$ outcomes, which are typically around $85 \%$. The favorable 5-7-year bDFS rates seen following SBRT may prove clinically relevant, as IMRT bDFS rates for intermediaterisk patients steadily drop beyond 5 years. Even at dose levels of $86.4 \mathrm{~Gy}, 10$-year relapse-free survival rate are around 75\% (83).

Mature data evaluating SBRT in high-risk prostate cancer are limited. The largest series is a pooled analysis of eight institutions (74), in which 125 high-risk patients received CyberKnife with or without androgen deprivation therapy (ADT). Five-year bDFS was favorable at $81 \%$. Katz (81) reported on a series of 97 high-risk patient treated with either five fractions CyberKnife (35-36.25 Gy) or CyberKnife boost (19-21 Gy in three fractions following $45 \mathrm{~Gy}$ pelvic RT). Forty-six of the 97 patients received ADT. Five-year bDFS was $68 \%$. The addition of pelvic radiotherapy or ADT had no impact on relapse-free survival, although pelvic RT was associated with greater GI toxicity.

\section{ANDROGEN DEPRIVATION THERAPY}

Androgen deprivation therapy is routinely added to conventional $\mathrm{RT}$ in unfavorable intermediate-risk and high-risk prostate cancer patients (84). In intermediate-risk patients, RTOG 94-08 (85) demonstrated an overall survival benefit when 4 months of neoadjuvant hormone therapy (NHT) was added to 66.6 Gy of external beam RT. We now know higher external beam doses yields better outcomes. However, even with modern dose-escalated external 
beam RT, ADT appears to benefit unfavorable intermediate-risk patients (86). ADT reduces both micrometastatic and local disease burden; the latter effect may make up for radiotherapy doses that are inadequate to sterilize the primary disease site. In patients treated with brachytherapy (which delivers higher biologic doses to the prostate), a benefit from ADT is unclear, as there are studies $(87,88)$ showing conflicting results. The only study evaluating the impact of ADT on SBRT showed no benefit (81). Even short-term ADT is associated with hot flashes, erectile dysfunction, muscle loss, fat accumulation, increased cholesterol, and decreased insulin sensitivity $(89,90)$. If dose-escalation obviates the need for ADT in some subgroups, then SBRT may allow some patients to avoid the toxicity of ADT. More research is needed in this area.

\section{SBRT TOXICITY}

Rates of late physician-reported GI and GU toxicities from mature SBRT series and from 3-D conformal, IMRT, proton, and LDR brachytherapy series are summarized in Table 5. Since median follow-up on the SBRT series is the 3-5-year range, these rates may underestimate the true rates of toxicities, as more toxicities may develop with longer follow-up. Nevertheless, Figure 2A, which illustrates the rates of grade $2+$ toxicities for various modalities, suggests SBRT late urinary toxicity rates compare favorably to external beam. Late rectal toxicity rates appear to be consistently less than those seen with external beam radiotherapy (Figure 2B). These series employed a robotic non-coplanar delivery platform which corrected for target motion in real-time (CyberKnife), although recent reports of SBRT employing conventional gantrybased platforms $(76,77)$ also suggest favorable toxicity. A recent study (91) comparing Medicare claims found SBRT was associated with 38\% more diagnoses of urethritis, incontinence, and obstruction, compared to IMRT. This study did not evaluate patients treated with G0339 and G0340 codes (used prior to 2014 with CyberKnife delivery), so the increased toxicity may be related to the differences in treatment technique and/or platforms. Finally, most SBRT series limited PTV doses to 35-40 Gy in five fractions. In a multi-center dose-escalation SBRT study (92), 5 of 91 patients treated to $50 \mathrm{~Gy}$ in five fractions required colostomy for rectal injury. This emphasizes the need to respect dose constraints for critical structures surrounding the prostate.

\section{PATIENT-REPORTED TOXICITY}

Following definitive therapy for prostate cancer, prospective patient-completed QOL questionnaires more accurately estimate treatment-related toxicity, compared to physician reports $(94,95)$. In Katz' report of 304 patients treated with CyberKnife SBRT, urinary and bowel QOL decreased immediately following treatment, and then returned to baseline. Patient-reported QOL outcomes from a prospective multi-institutional study (82) of 309 patients treated with CyberKnife are illustrated in Figures 3-6 below. QOL outcomes of various organ domains from the validated EPIC instrument are superimposed on the benchmark external beam and brachytherapy outcomes reported in Sanda's (96) study. Long-term changes in urinary incontinence scores following SBRT were similar to those observed in external beam and in brachytherapy (Figure 3). Urinary irritation/obstruction scores following SBRT appeared to be less adversely affected than after brachytherapy (Figure 4). While there were small changes in bowel QOL following SBRT (Figure 5), these declines appeared less prominent than following EBRT and brachytherapy. EPIC sexual score declined progressively during the 4 years after treatment (Figure 6). Because this methodology does not account for potential differences between SBRT and EBRT/LDR patient populations, no firm conclusions can be drawn. Nonetheless, these patient-reported SBRT QOL outcomes are encouraging.

\section{COST EFFECTIVENESS}

Although delivery of SBRT is technically more involved that IMRT, treatment is completed in only five fractions, rather than the 39-48 fractions required for IMRT. A Markov decision analysis model (97) showed the mean cost of $\$ 22,152$ for SBRT vs. $\$ 35,431$ for IMRT. Another study of Medicare claims (91) reported mean costs of $\$ 13,645$ and $\$ 21,023$ for SBRT and IMRT, respectively. These studies used SBRT billing codes, not the "robotic"

Table 5 | Toxicity rates for SBRT vs. EBRT, protons, brachytherapy.

\begin{tabular}{|c|c|c|c|c|c|c|c|c|}
\hline \multirow[t]{2}{*}{ Technique } & \multirow[t]{2}{*}{ Institution } & \multirow[t]{2}{*}{ Details } & \multirow[t]{2}{*}{ Median F/U years } & \multirow[t]{2}{*}{ Pts } & \multicolumn{2}{|c|}{$\begin{array}{l}\text { Late GU } \\
\text { toxicity (\%) }\end{array}$} & \multicolumn{2}{|c|}{$\begin{array}{l}\text { Late GI } \\
\text { toxicity (\%) }\end{array}$} \\
\hline & & & & & Gr2 & Gr3 & Gr2 & Gr3 \\
\hline \multirow[t]{4}{*}{ SBRT (CyberKnife) } & Stanford (73) & $7.25 \mathrm{~Gy} \times 5$ & 2.7 & 67 & 5.3 & 3.5 & 2.0 & 0 \\
\hline & Winthrop Hosp (78) & $7-7.25 \mathrm{~Gy} \times 5$ & 5.0 & 304 & 8.2 & 1.6 & 4.6 & 0 \\
\hline & San Bortolo Hosp (80) & $7 \mathrm{~Gy} \times 5$ & 3.0 & 100 & 3.0 & 1.0 & 1.0 & 0 \\
\hline & Multi-institutional (75) & $8 \mathrm{~Gy} \times 5$ & 3.0 & 137 & 11.0 & 0.8 & 1.0 & 0 \\
\hline \multirow[t]{2}{*}{ 3-D-Conf RT } & Dutch Random Trial (27) & $78.0 \mathrm{~Gy}$ & 4.2 & 333 & 26.0 & 13.0 & 27.0 & 5.0 \\
\hline & MDA Random Trial (93) & $78.0 \mathrm{~Gy}$ & 8.7 & 151 & 7.3 & 3.3 & 19.0 & 6.6 \\
\hline IMRT & Memorial SKCC (83) & $86.4 \mathrm{~Gy}$ & 4.4 & 478 & 13.0 & 2.5 & 3.3 & 0.4 \\
\hline Protons & MGH PROG (22) & $79.2 \mathrm{~Gy}$ & 8.9 & 196 & 21.0 & 1.5 & 24.0 & 1.0 \\
\hline LDR & RTOG 9805 (16) & 145 Gy & 8.1 & 94 & 20.0 & 3.1 & 5.0 & 0 \\
\hline
\end{tabular}

SBRT, stereotactic body radiotherapy; IMRT, intensity-modulated radiotherapy; $L D R$, low-dose rate brachytherapy; $R T$, radiation therapy. 

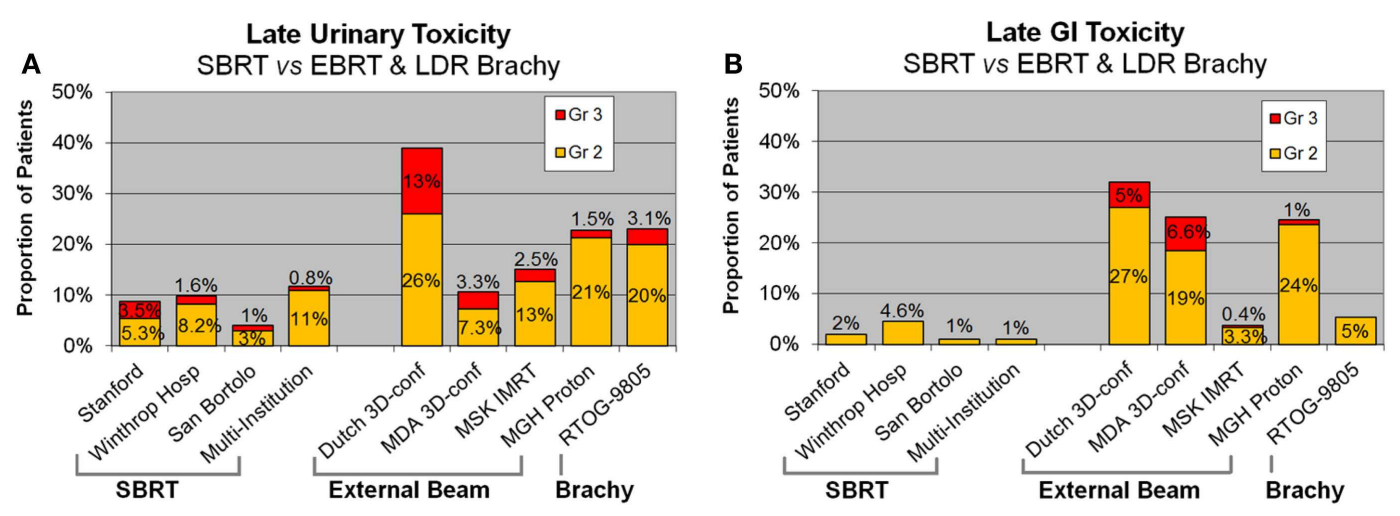

FIGURE 2 | Late urinary (A) and GI (B) toxicity rates following SBRT, external beam radiotherapy, and brachytherapy. SBRT, stereotactic body radiotherapy.
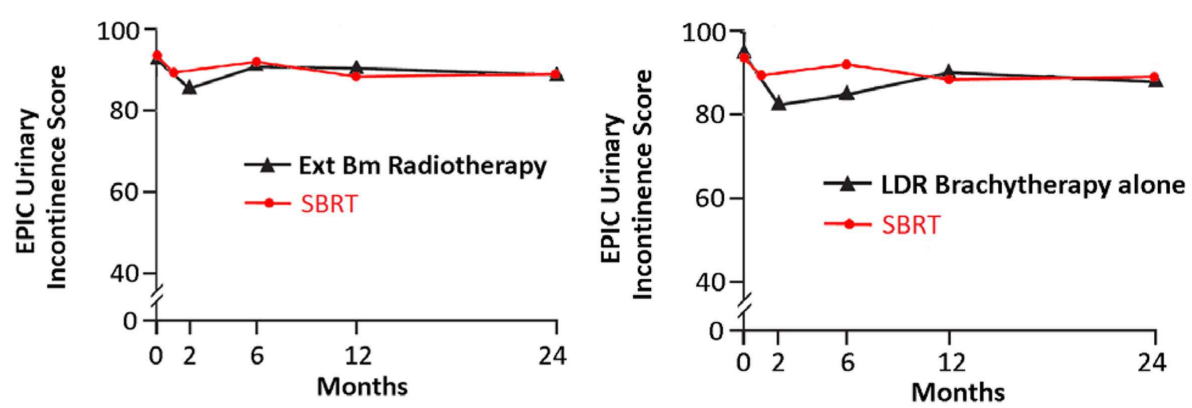

FIGURE 3 | EPIC urinary incontinence scores at baseline and at various intervals following treatment (months) from Sanda (96) (black: left graph is for external beam RT and right is for brachytherapy) and SBRT (red). SBRT, stereotactic body radiotherapy; RT, radiation therapy.
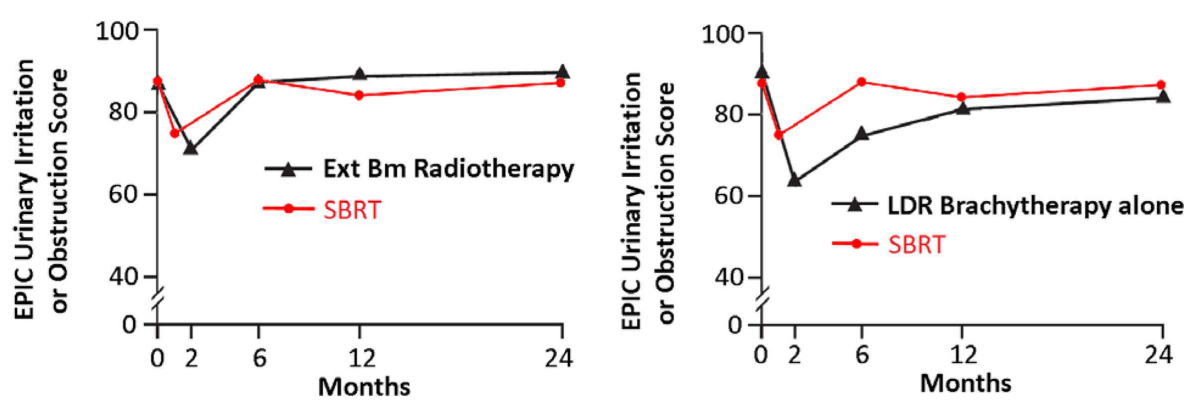

FIGURE 4 | EPIC urinary irritation/obstruction scores at baseline and at various intervals following treatment (months) from Sanda (96) (black: left graph is external beam RT and right is brachytherapy) and SBRT (red). SBRT, stereotactic body radiotherapy; RT, radiation therapy.

G-codes used before 2014 for CyberKnife treatment. Since January 1, 2014, CyberKnife treatment also uses the same SBRT codes, thus these figures are relevant for robotic and non-robotic delivery. In addition to the cost for treatment, conventionally fractionated radiotherapy has a substantial time-cost to patients (98), which is mitigated by the far shorter treatment courses employed with SBRT.

\section{ONGOING STUDIES}

The reported outcomes of SBRT in prostate cancer are derived from prospective non-randomized studies with the longest median follow-up extending to approximately 5 years. While these outcomes appear favorable relative to other radiation modalities, caution is warranted before concluding SBRT should supplant conventionally fractionated external beam RT. SBRT target doses, 

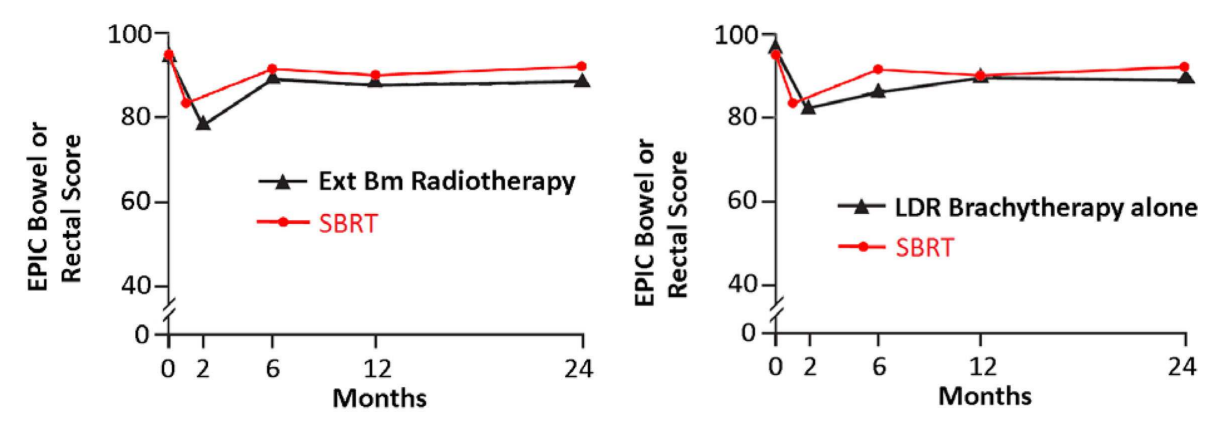

FIGURE 5 | EPIC bowel scores at baseline and at various intervals following treatment (months) from Sanda (96) (black: left graph is external beam RT and right is brachytherapy) and SBRT (red). SBRT, stereotactic body radiotherapy; RT, radiation therapy.
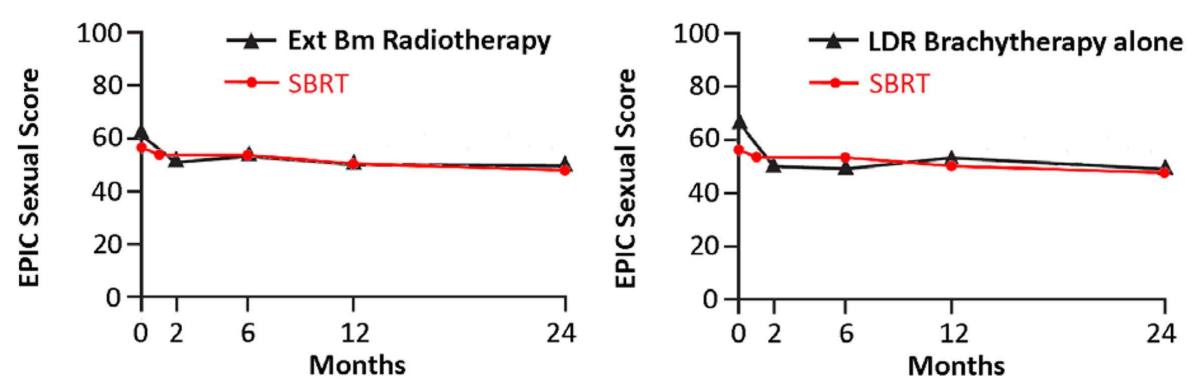

FIGURE 6 | EPIC sexual scores at baseline and at various intervals following treatment (months) from Sanda (96) (black: left graph is external beam RT and right is brachytherapy) and SBRT (red). SBRT, stereotactic body radiotherapy; RT, radiation therapy.

Table 6 | Randomized SBRT trials registered on clinicaltrials.gov, ISRCTN, and cancerresearchUK.org.

\begin{tabular}{|c|c|c|c|}
\hline Institution/study & Eligibility & Arms & Primary outcomes \\
\hline Curie Institute Poland, NCT01839994 & T1-T3a N0 M0 & $\begin{array}{l}\text { 76-78 Gy, } 2 \text { Gy/fx } \\
50 \text { Gy EBRT }+10 \text { Gy } \times 2 \text { SBRT/HDR boost }\end{array}$ & bDFS, toxicity \\
\hline University of Miami, NCT01794403 & $\begin{array}{l}\text { T1-T2 No M0, low-, } \\
\text { intermediate-risk }\end{array}$ & $\begin{array}{l}70.2 \mathrm{~Gy}, 2.7 \mathrm{~Gy} / \mathrm{fx} \text { IMRT } \\
36.25 \mathrm{~Gy}, 5 \text { fxs SBRT }\end{array}$ & 2-year bDFS \\
\hline University Hosp Geneva, NCT01764646 & T1-T3a N0 M0 & $\begin{array}{l}\text { 36.25 Gy SBRT } 9 \text { days } \\
36.25 \text { Gy SBRT once/week }\end{array}$ & Acute, late toxicity \\
\hline Swedish HYPO-RT-PC, ISRCTN45905321 & Intermediate-risk & $\begin{array}{l}78 \mathrm{~Gy}, 2 \mathrm{~Gy} / \mathrm{fx} \mathrm{RT} \\
42.7 \mathrm{~Gy}, 6.1 \mathrm{~Gy} / \mathrm{fx}\end{array}$ & bDFS \\
\hline Royal Marsden PACE, CRUKE/12/025 & T1-T2 N0 M0 & $\begin{array}{l}\text { Prostatectomy vs. SBRT ( } 36.25-38 \mathrm{~Gy}, 4-5 \mathrm{fxs}) \\
\text { SBRT vs. conventional RT ( } 78 \mathrm{~Gy}, 2 \mathrm{~Gy} / \mathrm{fx})\end{array}$ & 5-year bDFS \\
\hline
\end{tabular}

techniques of RT delivery, image-guidance approaches, and normal tissue constraints vary considerably between series, making comparisons difficult. While SBRT toxicities at 3-5 years appear favorable, higher rates of GU toxicity may be observed with longer follow-up. Finally, non-randomized comparisons are inherently uncertain. Firm conclusions about the efficacy and toxicity of SBRT relative to more conventional approaches await scrutiny by prospective randomized trials. Randomized trials registered on clinicaltrials.gov, ISRCTN registry, and cancerresearchUK.org are summarized in Table 6.

\section{CONCLUSION}

Stereotactic body radiotherapy offers a cost-effective alternative to external beam radiotherapy which is much more convenient for the patient. The radiobiology of prostate cancer would predict that this approach should yield superior outcomes compared to conventional protracted courses. For low-and intermediate-risk prostate cancer patients treated on a robotic, non-coplanar RT platform, 5-year relapse-free survival rates are at least equivalent, or possibly superior to conventionally fractionated RT. Physicianreported late urinary toxicity appears to be similar to external 
beam RT, and late GI toxicity appears to be less than with external beam and LDR brachytherapy. Patient-reported QOL outcomes show urinary and bowel function return to near baseline levels 2 years following robotic SBRT. Long-term changes in rectal QOL appear to be superior to those reported after IMRT or LDR brachytherapy. For high-risk prostate cancer, initial CyberKnife series suggest favorable outcomes. Emerging outcomes in low-risk patients treated on gantry-based platforms are similarly encouraging. A prospective randomized trial would be required to confirm these favorable SBRT outcomes relative to other modalities. But given these excellent cancer control rates and toxicity profiles, SBRT delivered on platforms which have real-time image guidance appears to be an acceptable approach for stage I-II prostate cancer. Further studies are also required to determine if similar favorable outcomes are possible with SBRT delivered on other platforms, and in patients with high-risk disease.

\section{REFERENCES}

1. Siegel R, Ma J, Zou Z, et al. Cancer statistics, 2014. CA Cancer J Clin (2014) 64:9-29. doi:10.3322/caac.21208

2. Paquette EL, Sun L, Paquette LR, Connelly R, McLeod DG, Moul JW. Improved prostate cancer-specific survival and other disease parameters: impact of prostate specific antigen testing. Urology (2002) 60:756-9. doi:10.1016/S00904295(02)01960-X

3. Edge SB, Byrd DR, Compton CC, et al. editors. AJCC Cancer Staging Manual. 7 th ed. New York, NY: Springer (2010).

4. Shao YH, Demissie K, Shih W, Mehta AR, Stein MN, Roberts CB, et al. Contemporary risk profile of prostate cancer in the United States. J Natl Cancer Inst (2009) 101:1280-3. doi:10.1093/jnci/djp262

5. Klotz L, Zhang L, Lam A, et al. Clinical results of long-term follow-up of a large, active surveillance cohort with localized prostate cancer. J Clin Oncol (2010) 28:126-31. doi:10.1200/JCO.2009.24.2180

6. Thompson I, Thrasher JB, Aus G, Burnett AL, Canby-Hagino ED, Cookson MS, et al. Guideline for the management of clinically localized prostate cancer: 2007 update. J Urol (2007) 177(6):2106-31. doi:10.1016/j.juro.2007.03.003

7. Deming CL. Results in one hundred cases of cancer of prostate and seminal vesicles, treated with radium. Surg Gynaecol Obstet (1922) 34:99-118.

8. Hultberg S. Results of treatment with radiotherapy in carcinoma of the prostate. Acta Radiol (1946) 27:339-50. doi:10.3109/00016924609135192

9. Bagshaw MA, Kaplan HS, Sagerman RH. Linear accelerator supervoltage radiotherapy. VII. Carcinoma of the prostate. Radiology (1965) 95:121-9. doi:10.1148/85.1.121

10. Budhraja SN, Anderson JC. An assessment of the value of radiotherapy in the management of carcinoma of the prostate. Br J Urol (1964) 36:535-40. doi:10.1111/j.1464-410X.1964.tb09544.x

11. George FW, Carlton CE Jr, Dykhuizen RF, Dillon JR. Cobalt-60 telecurietherapy in the definitive treatment of carcinoma of the prostate: a preliminary report. $J$ Urol (1965) 93:102-9.

12. Galalae RM, Martinez A, Mate T, Mitchell C, Edmundson G, Nuernberg N, et al. Long-term outcome by risk factors using conformal high-dose-rate brachytherapy (HDR-BT) boost with or without neoadjuvant androgen suppression for localized prostate cancer. Int J Radiat Oncol Biol Phys (2004) 58:1048-55. doi:10.1016/j.ijrobp.2003.08.003

13. Demanes DJ, Rodriguez RR, Schour L, Brandt D, Altieri G. High-doserate intensity-modulated brachytherapy with external beam radiotherapy for prostate cancer: California endocurietherapy's 10-year results. Int J Radiat Oncol Biol Phys (2005) 61:1306-16. doi:10.1016/j.ijrobp.2004.08.014

14. Schour L, Demanes DJ, Altieri GA, Brandt D, Barnaba M, Skoolisariyaporn P. High dose rate monotherapy for prostate cancer. Int J Radiat Oncol Biol Phys (2005) 63:S315. doi:10.1016/j.ijrobp.2005.07.540

15. Ghilezan M, Vargas C, Gustafson G, Boike T, Chao K, Kestin L, et al. Similar 5-year clinical outcome for high dose rate (HDR) and low dose rate (LDR) brachytherapy (BT) for early prostate cancer patients. Int J Radiat Oncol Biol Phys (2005) 63:S37. doi:10.1016/j.ijrobp.2005.07.068
16. Lawton CA, Hunt D, Lee WR, Gomella L, Grignon D, Gillin M, et al. Results of a phase II trial of transrectal ultrasound-guided permanent radioactive implantation of the prostate for definitive management of localized adenocarcinoma of the prostate (RTOG 98-05). Int J Radiat Oncol Biol Phys (2007) 67:39-47. doi:10.1016/j.ijrobp.2010.05.056

17. Zelefsky MJ, Kuban DA, Levy LB, Potters L, Beyer DC, Blasko JC, et al. Multiinstitutional analysis of long-term outcome for stages T1-T2 prostate cancer treated with permanent seed implantation. Int J Radiat Oncol Biol Phys (2007) 67:327-33. doi:10.1016/j.ijrobp.2006.08.056

18. Kupelian PA, Thakkar VV, Khuntia D, Reddy CA, Klein EA, Mahadevan A. Hypofractioned intensity-modulated radiotherapy (70Gy at 2.5 Gy per fraction) for localized prostate cancer: long-term outcomes. Int J Radiat Oncol Biol Phys (2005) 63:1463-8. doi:10.1016/j.ijrobp.2005.05.054

19. Zelefsky MJ, Chan H, Hunt M, Yamada Y, Shippy AM, Amols H. Long-term outcome of high dose intensity modulated radiation therapy for patients with clinically localized prostate cancer. J Urol (2006) 176:1415-9. doi:10.1016/j.juro. 2006.06.002

20. Kupelian P, Kuban D, Thames H, Levy L, Horwitz E, Martinez A, et al. Improved biochemical relapse-free survival with increased external radiation doses in patients with localized prostate cancer: the combined experience of nine institutions in patients treated in 1994 and 1995. Int J Radiat Oncol Biol Phys (2005) 61:415-9. doi:10.1016/j.ijrobp.2004.05.018

21. Cheung R, Tucker SL, Lee AK, de Crevoisier R, Dong L, Kamat A, et al. Dose-response characteristics of low- and intermediate-risk prostate cancer treated with external beam radiotherapy. Int J Radiat Oncol Biol Phys (2005) 61:993-1002. doi:10.1016/j.ijrobp.2004.04.064

22. Zietman AL, Bae K, Slater JD, Shipley WU, Efstathiou JA, Coen JJ, et al. Randomized trial comparing conventional-dose with high-dose conformal radiation therapy in early-stage adenocarcinoma of the prostate: long-term results from proton radiation oncology group/American college of radiology 95-09. J Clin Oncol (2010) 28:1106-11. doi:10.1200/JCO.2009.25.8475

23. Hull GW, Rabbani F, Abbas F, Wheeler TM, Kattan MW, Scardino PT. Cancer control with radical prostatectomy alone in 1,000 consecutive patients. $J$ Urol (2002) 167:528-34. doi:10.1016/S0022-5347(01)69079-7

24. Kupelian PA, Potters L, Khuntia D, Ciezki JP, Reddy CA, Reuther AM, et al. Radical prostatectomy, external beam radiotherapy $<72$ Gy, external beam radiotherapy $>$ or $=72 \mathrm{~Gy}$, permanent seed implantation, or combined seeds/external beam radiotherapy for stage T1-T2 prostate cancer. Int J Radiat Oncol Biol Phys (2004) 58:25-33. doi:10.1016/S0360-3016(03)00784-3

25. D’Amico AV, Whittington R, Malkowicz SB, Schultz D, Blank K, Broderick GA, et al. Biochemical outcome after radical prostatectomy, external beam radiation therapy, or interstitial radiation therapy for clinically localized prostate cancer. JAMA (1998) 280:969-74. doi:10.1001/jama.280.11.969

26. Han M, Partin AW, Zahurak M, Piantadosi S, Epstein JI, Walsh PC. Biochemical (prostate specific antigen) recurrence probability following radical prostatectomy for clinically localized prostate cancer. J Urol (2003) 169:517-23. doi:10.1097/00005392-200302000-00018

27. Peeters ST, Heemsbergen WD, Koper PC, van Putten WL, Slot A, Dielwart MF, et al. Dose-response in radiotherapy for localized prostate cancer: results of the Dutch multicenter randomized phase III trial comparing 68 Gy of radiotherapy with 78 Gy. J Clin Oncol (2006) 24:1990-6. doi:10.1200/JCO.2005. 05.2530

28. Pollack A, Zagars GK, Starkschall G, Antolak JA, Lee JJ, Huang E, et al. Prostate cancer radiation dose response: results of the M. D. Anderson phase III randomized trial. Int J Radiat Oncol Biol Phys (2002) 53:1097-105. doi:10.1016/S03603016(02)02829-8

29. Fowler JF, Ritter MA, Chappell RJ, Brenner DJ. What hypofractionated protocols should be tested for prostate cancer? Int J Radiat Oncol Biol Phys (2003) 56:1093-104. doi:10.1016/S0360-3016(03)00132-9

30. Viani GA, Stefano EJ, Afonso SL. Higher-than-conventional radiation doses in localized prostate cancer treatment: a meta-analysis of randomized, controlled trials. Int J Radiat Oncol Biol Phys (2009) 74:1405-18. doi:10.1016/j.ijrobp.2008. 10.091

31. Kupelian P, Willoughby T, Mahadevan A, Djemil T, Weinstein G, Jani S, et al. Multi-institutional clinical experience with the Calypso System in localization and continuous, real-time monitoring of the prostate gland during external radiotherapy. Int J Radiat Oncol Biol Phys (2007) 67:1088-98. doi:10.1016/j. ijrobp.2006.10.026 
32. Beltran C, Herman MG, Davis BJ. Planning target margin calculations for prostate radiotherapy based on intrafraction and interfraction motion using four localization methods. Int J Radiat Oncol Biol Phys (2008) 70:289-95. doi:10.1016/j.ijrobp.2007.08.040

33. Sheets NC, Goldin GH, Meyer AM, Wu Y, Chang Y, Stürmer T, et al. Intensitymodulated radiation therapy, proton therapy, or conformal radiation therapy and morbidity and disease control in localized prostate cancer. JAMA (2012) 307:1611-20. doi:10.1001/jama.2012.460

34. Coen JJ, Bae K, Zietman AL, Patel B, Shipley WU, Slater JD, et al. Acute and late toxicity after dose escalation to $82 \mathrm{GyE}$ using conformal proton radiation for localized prostate cancer: initial report of American college of radiology Phase II study 03-12. Int J Radiat Oncol Biol Phys (2011) 81:1005-9. doi:10.1016/j.ijrobp.2010.06.047

35. Blasko JC, Grimm PD, Sylvester JE, Badiozamani KR, Hoak D, Cavanagh W. Palladium-103 brachytherapy for prostate carcinoma. Int J Radiat Oncol Biol Phys (2000) 46:839-50. doi:10.1016/S0360-3016(99)00499-X

36. Grimm PD, Blasko JC, Sylvester JE, Meier RM, Cavanagh W. 10-year biochemical (prostate-specific antigen) control of prostate cancer with (125)I brachytherapy. Int J Radiat Oncol Biol Phys (2001) 51:31-40. doi:10.1016/S0360-3016(01) 01601-7

37. Stone NN, Stock RG, Unger P. Intermediate term biochemical-free progression and local control following 125iodine brachytherapy for prostate cancer. J Urol (2005) 173:803-7. doi:10.1097/01.ju.0000152558.63996.29

38. Potters L, Morgenstern C, Calugaru E, Fearn P, Jassal A, Presser J, et al. 12-year outcomes following permanent prostate brachytherapy in patients with clinically localized prostate cancer. J Urol (2005) 173:1562-6. doi:10.1097/01.ju. $0000154633.73092 .8 \mathrm{e}$

39. Merrick GS, Butler WM, Wallner KE, Galbreath RW, Lief JH, Allen Z, et al. Impact of supplemental external beam radiotherapy and/or androgen deprivation therapy on biochemical outcome after permanent prostate brachytherapy. Int J Radiat Oncol Biol Phys (2005) 61:32-43. doi:10.1016/j.ijrobp.2004.05.003

40. Stock RG, Stone NN, Cesaretti JA, Rosenstein BS. Biologically effective dose values for prostate brachytherapy: effects on PSA failure and posttreatment biopsy results. Int J Radiat Oncol Biol Phys (2006) 64:527-33. doi:10.1016/j.ijrobp.2005. 07.981

41. Eade TN, Horwitz EM, Ruth K, Buyyounouski MK, D’Ambrosio DJ, Feigenberg SJ, et al. A comparison of acute and chronic toxicity for men with lowrisk prostate cancer treated with intensity-modulated radiation therapy or (125)I permanent implant. Int J Radiat Oncol Biol Phys (2008) 71:338-45. doi:10.1016/j.ijrobp.2007.10.019

42. Sanda MG, Dunn RL, Michalski J, Sandler HM, Northouse L, Hembroff L, et al. Quality of life and satisfaction with outcome among prostate-cancer survivors. N Engl J Med (2008) 358:1250-61. doi:10.1056/NEJMoa074311

43. Borghede G, Hedelin H, Holmäng S, Johansson KA, Sernbo G, Mercke C. Irradiation of localized prostatic carcinoma with a combination of high dose rate iridium-192 brachytherapy and external beam radiotherapy with three target definitions and dose levels inside the prostate gland. Radiother Oncol (1997) 44:245-50. doi:10.1016/S0167-8140(97)00122-9

44. Martinez A, Gonzalez J, Stromberg J, Edmundson G, Plunkett M, Gustafson $\mathrm{G}$, et al. Conformal prostate brachytherapy: initial experience of a phase I/II dose-escalating trial. Int J Radiat Oncol Biol Phys (1995) 33:1019-27. doi:10.1016/0360-3016(95)00254-5

45. Martinez AA, Pataki I, Edmundson G, Sebastian E, Brabbins D, Gustafson G. Phase II prospective study of the use of conformal high-dose-rate brachytherapy as monotherapy for the treatment of favorable stage prostate cancer: a feasibility report. Int J Radiat Oncol Biol Phys (2001) 49:61-9. doi:10.1016/S0360-3016(00) 01463-2

46. Mate TP, Gottesman JE, Hatton J, Gribble M, Van Hollebeke L. High dose-rate after loading 192Iridium prostate brachytherapy: feasibility report. Int J Radiat Oncol Biol Phys (1998) 41:525-33. doi:10.1016/S0360-3016(98)00097-2

47. Kestin LL, Martinez AA, Stromberg JS, Edmundson GK, Gustafson GS, Brabbins DS, et al. Matched-pair analysis of conformal high-dose-rate brachytherapy boost versus external-beam radiation therapy alone for locally advanced prostate cancer. J Clin Oncol (2000) 18:2869-80.

48. Kovács G, Galalae R, Loch T, Bertermann H, Kohr P, Schneider R, et al. Prostate preservation by combined external beam and HDR brachytherapy in nodal negative prostate cancer. Strahlenther Onkol (1999) 175:87-8. doi:10.1007/ BF03038899
49. Galalae RM, Kovács G, Schultze J, Loch T, Rzehak P, Wilhelm R, et al. Long-term outcome after elective irradiation of the pelvic lymphatics and local dose escalation using high-dose-rate brachytherapy for locally advanced prostate cancer. Int J Radiat Oncol Biol Phys (2002) 52:81-90. doi:10.1016/S0360-3016(01) 01758-8

50. Stromberg J, Martinez A, Gonzalez J, Edmundson G, Ohanian N, Vicini F, et al. Ultrasound-guided high dose rate conformal brachytherapy boost in prostate cancer: treatment description and preliminary results of a phase I/II clinical trial. Int J Radiat Oncol Biol Phys (1995) 33:161-71. doi:10.1016/0360-3016(95) 00035-W

51. Grills IS, Martinez AA, Hollander M, Huang R, Goldman K, Chen PY, et al. High dose rate brachytherapy as prostate cancer monotherapy reduces toxicity compared to low dose rate palladium seeds. J Urol (2004) 171:1098-104. doi:10.1097/01.ju.0000113299.34404.22

52. Martin T, Baltas D, Kurek R, Röddiger S, Kontova M, Anagnostopoulos G, et al. 3-D conformal HDR brachytherapy as monotherapy for localized prostate cancer. A pilot study. Strahlenther Onkol (2004) 180:225-32. doi:10.1007/s00066004-1215-4

53. Mark R, Vallabhan G, Akins A, Anderson P, Nair M, Neumann T, et al. Interstitial high dose rate (HDR) brachytherapy for early stage prostate cancer. Int J Radiat Oncol Biol Phys (2005) 63:S304. doi:10.1016/j.ijrobp.2005.07.521

54. Saputo K, Isler K, Wallace M, Balasubramaniam M, Martinez A. A quality of life (QOL) assessment of prostate cancer patients undergoing different radiation treatment modalities. Int J Radiat Oncol Biol Phys (2005) 63:S446. doi:10.1016/j.ijrobp.2005.07.762

55. Williams MV, Denekamp J, Fowler JF. A review of alpha/beta ratios for experimental tumors: implications for clinical studies of altered fractionation. Int $J$ Radiat Oncol Biol Phys (1985) 11:87-96. doi:10.1016/0360-3016(85)90366-9

56. Brenner DJ, Hall EJ. Fractionation and protraction for radiotherapy of prostate carcinoma. Int J Radiat Oncol Biol Phys (1999) 43:1095-101. doi:10.1016/S03603016(98)00438-6

57. King CR, Fowler JF. A simple analytic derivation suggests that prostate cancer alpha/beta ratio is low. Int J Radiat Oncol Biol Phys (2001) 51:213-4. doi:10.1016/S0360-3016(01)01651-0

58. Fowler J, Chappell R, Ritter M. Is alpha/beta for prostate tumors really low? Int J Radiat Oncol Biol Phys (2001) 50:1021-31. doi:10.1016/S0360-3016(01)01607-8

59. Brenner DJ, Martinez AA, Edmundson GK, Mitchell C, Thames HD, Armour EP. Direct evidence that prostate tumors show high sensitivity to fractionation (low alpha/beta ratio), similar to late-responding normal tissue. Int J Radiat Oncol Biol Phys (2002) 52:6-13. doi:10.1016/S0360-3016(01)02664-5

60. Proust-Lima C, Taylor JM, Sécher S, Sandler H, Kestin L, Pickles T, et al. Confirmation of a low $\alpha / \beta$ ratio for prostate cancer treated by external beam radiation therapy alone using a post-treatment repeated-measures model for PSA dynamics. Int J Radiat Oncol Biol Phys (2011) 79:195-201. doi:10.1016/j.ijrobp.2009. 10.008

61. Lee WR, Hanks GE, Corn BW, Schultheiss TE. Observations of pretreatment prostate-specific antigen doubling time in 107 patients referred for definitive radiotherapy. Int J Radiat Oncol Biol Phys (1995) 31:21-4. doi:10.1016/03603016(94)00339-M

62. Haustermans KM, Hofland I, Van Poppel H, Oyen R, Van de Voorde W, Begg $\mathrm{AC}$, et al. Cell kinetic measurements in prostate cancer. Int J Radiat Oncol Biol Phys (1997) 37:1067-70. doi:10.1016/S0360-3016(96)00579-2

63. D'Souza WD, Thames HD. Is the alpha/beta ratio for prostate cancer low? Int J Radiat Oncol Biol Phys (2001) 51:1-3. doi:10.1016/S0360-3016(01)01650-9

64. Duchesne GM, Peters LJ. What is the alpha/beta ratio for prostate cancer? Rationale for hypofractionated high-dose-rate brachytherapy. Int J Radiat Oncol Biol Phys (1999) 44:747-8.

65. Fowler JF, Chappell RJ, Ritter MA. The prospects for new treatments for prostate cancer. Int J Radiat Oncol Biol Phys (2002) 52:3-5. doi:10.1016/S0360-3016(01) 02665-7

66. Kupelian PA, Willoughby TR, Reddy CA, Klein EA, Mahadevan A. Hypofractionated intensity-modulated radiotherapy (70 Gy at 2.5 Gy per fraction) for localized prostate cancer: Cleveland clinic experience. Int J Radiat Oncol Biol Phys (2007) 68:1424-30. doi:10.1016/j.ijrobp.2007.01.067

67. Yeoh EE, Botten RJ, Butters J, Di Matteo AC, Holloway RH, Fowler J. Hypofractionated versus conventionally fractionated radiotherapy for prostate carcinoma: final results of phase III randomized trial. Int J Radiat Oncol Biol Phys (2011) 81:1271-8. doi:10.1016/j.ijrobp.2010.07.1984 
68. Arcangeli S, Strigari L, Gomellini S, Saracino B, Petrongari MG, Pinnarò P, et al. Updated results and patterns of failure in a randomized hypofractionation trial for high-risk prostate cancer. Int J Radiat Oncol Biol Phys (2012) 84:1172-8. doi:10.1016/j.ijrobp.2012.02.049

69. Xie Y, Djajaputra D, King CR, Hossain S, Ma L, Xing L. Intrafractional motion of the prostate during hypofractionated radiotherapy. Int J Radiat Oncol Biol Phys (2008) 72:236-46. doi:10.1016/j.ijrobp.2008.04.051

70. Hossain S, Xia P, Huang K, Descovich M, Chuang C, Gottschalk AR, et al. Dose gradient near target-normal structure interface for nonisocentric CyberKnife and isocentric intensity-modulated body radiotherapy for prostate cancer. Int $\mathrm{J}$ Radiat Oncol Biol Phys (2010) 78:58-63. doi:10.1016/j.ijrobp.2009.07.1752

71. Madsen BL, Hsi RA, Pham HT, Fowler JF, Esagui L, Corman J. Stereotactic hypofractionated accurate radiotherapy of the prostate (SHARP), 33.5 Gy in five fractions for localized disease: first clinical trial results. Int J Radiat Oncol Biol Phys (2007) 67:1099-105. doi:10.1016/j.ijrobp.2006.10.050

72. King CR, Lehmann J, Adler JR, Hai J. CyberKnife radiotherapy for localized prostate cancer: rationale and technical feasibility. Technol Cancer Res Treat (2003) 2:25-30. doi:10.1177/153303460300200104

73. King CR, Brooks JD, Gill H, Presti JC Jr. Long-term outcomes from a prospective trial of stereotactic body radiotherapy for low-risk prostate cancer. Int J Radiat Oncol Biol Phys (2012) 82:877-82. doi:10.1016/j.ijrobp.2010.11.054

74. King CR, Freeman D, Kaplan I, Fuller D, Bolzicco G, Collins S, et al. Stereotactic body radiotherapy for localized prostate cancer: pooled analysis from a multiinstitutional consortium of prospective phase II trials. Radiother Oncol (2013) 109:217-21. doi:10.1016/j.radonc.2013.08.030

75. Meier R, Cotrutz C, Loiselle C, Sima S, Vermeulen S. Long-term outcomes of stereotactic body radiation therapy for organ-confined prostate cancer. Int J Radiat Oncol Biol Phys (2012) 84:S148. doi:10.1016/j.ijrobp.2012.07.1103

76. Loblaw D, Sethukavalan P, Cheung P, Morton G, D'Alimonte L, Deabreu A, et al. Comparison of biochemical and toxicity outcomes from a contemporaneous cohort study of low-risk prostate cancer treated with different radiation techniques. Int J Radiat Oncol Biol Phys (2013) 87:S26. doi:10.1016/j.ijrobp. 2013.06.071

77. Mantz CA, Fernandez E. Real-time target tracking prostate SBRT and the realtime tracking system 4D localization system: 5-year quality of life and disease outcomes. Int J Radiat Oncol Biol Phys (2013) 87:S393. doi:10.1016/j.ijrobp. 2013.06.1030

78. Katz A, Kang J. Stereotactic body radiotherapy as treatment for organ confined low-and intermediate-risk prostate carcinoma, a 7-year study. Front Oncol (2014) 4:240. doi:10.3389/fonc. 2014.00240

79. Freeman DE, King CR. Stereotactic body radiotherapy for low-risk prostate cancer: five-year outcomes. Radiat Oncol (2011) 6:3. doi:10.1186/1748-717X-6-3

80. Bolzicco G, Favretto MS, Satariano N, Scremin E, Tambone C, Tasca A. A single-center study of 100 consecutive patients with localized prostate cancer treated with stereotactic body radiotherapy. BMC Urol (2013) 13:49. doi:10.1186/1471-2490-13-49

81. Katz A, Kang J. Stereotactic body radiotherapy with or without external beam radiation as treatment for organ confined high-risk prostate carcinoma: a six year study. Radiat Oncol (2014) 9:1. doi:10.1186/1748-717X-9-1

82. Meier R, Kaplan I. Quality of life outcomes from a multicenter study of SBRT for low- and intermediate-risk prostate cancer. Presented at the 33rd Annual Meeting of ESTRO. Vienna: (2014).

83. Spratt DE, Pei X, Yamada J, Kollmeier MA, Cox B, Zelefsky MJ. Long-term survival and toxicity in patients treated with high-dose intensity modulated radiation therapy for localized prostate cancer. Int J Radiat Oncol Biol Phys (2013) 85:686-92. doi:10.1016/j.ijrobp.2012.05.023

84. Roach M. Current trends for the use of androgen deprivation therapy in conjunction with radiotherapy for patients with unfavorable intermediaterisk, high-risk, localized, and locally advanced prostate cancer. Cancer (2014) 120(11):1620-9. doi:10.1002/cncr.28594

85. Jones C. Radiotherapy and short-term androgen deprivation for localized prostate cancer. N Engl J Med (2011) 365(2):107-18. doi:10.1056/ NEJMoa1012348
86. Bian S. Addition of short-term androgen deprivation therapy to doseescalated radiation therapy improves failure-free survival for select men with intermediate-risk prostate cancer. Ann Oncol (2012) 23(9):2346-52. doi:10. 1093/annonc/mds001

87. Stone N. Multicenter analysis of effect of high biologic effective dose on biochemical failure and survival outcomes in patients with Gleason score 7-10 prostate cancer treated with permanent prostate brachytherapy. Int J Radiat Oncol Biol Phys (2009) 73(2):341-6. doi:10.1016/j.ijrobp.2008.04.038

88. Potters L. 12-year outcomes following permanent prostate brachytherapy in patients with clinically localized prostate cancer. J Urol (2005) 173(5):1562-6. doi:10.1097/01.ju.0000154633.73092.8e

89. Watkins Bruner D. Randomized, double-blinded, placebo-controlled crossover trial of treating erectile dysfunction with sildenafil after radiotherapy and shortterm androgen deprivation therapy: results of RTOG 0215. J Sex Med (2011) 8(4):1228-38. doi:10.1111/j.1743-6109.2010.02164.x

90. Saylor P. Metabolic complications of androgen deprivation therapy for prostate cancer. J Urol (2009) 181(5):1998-2008. doi:10.1016/j.juro.2009.01.047

91. Yu JB, Cramer LD, Herrin J, Soulos PR, Potosky AL, Gross CP. Stereotactic body radiation therapy versus intensity-modulated radiation therapy for prostate cancer: comparison of toxicity. J Clin Oncol (2014) 32:1195-201. doi:10.1200/JCO.2013.53.8652

92. Kim DWN, Cho LC, Straka C, Christie A, Lotan Y, Pistenmaa D, et al. Predictors of rectal tolerance observed in a dose-escalated phase 1-2 trial of stereotactic body radiation therapy for prostate cancer. Int J Radiat Oncol Biol Phys (2014) 89:509-17. doi:10.1016/j.ijrobp.2014.03.012

93. Kuban DA, Tucker SL, Dong L, Starkschall G, Huang EH, Cheung MR, et al. Long-term results of the M.D. Anderson randomized dose-escalation trial for prostate cancer. Int J Radiat Oncol Biol Phys (2008) 70:67-74. doi:10.1016/j. ijrobp.2007.06.054

94. Litwin MS, Hays RD, Fink A, Ganz PA, Leake B, Leach GE, et al. Quality-of-life outcomes in men treated for localized prostate cancer. JAMA (1995) 273:129-35. doi:10.1001/jama.1995.03520260051032

95. Talcott JA, Rieker P, Clark JA, Propert KJ, Weeks JC, Beard CJ, et al. Patientreported symptoms after primary therapy for early prostate cancer: results of a prospective cohort study. J Clin Oncol (1998) 16:275-83.

96. Sanda MG, Dunn RL, Michalski J, Sandler HM, Northouse L, Hembroff L, et al. Quality of life and satisfaction with outcome among prostate-cancer survivors. N Engl J Med (2008) 358:1250-61. doi:10.1056/NEJMoa074311

97. Hodges JC, Lotan Y, Boike TP, Benton R, Barrier A, Timmerman RD. Costeffectiveness analysis of stereotactic body radiation therapy versus intensitymodulated radiation therapy: an emerging initial radiation treatment option for organ-confined prostate cancer. J Oncol Pract (2012) 8:31s-7s. doi:10.1200/ JOP.2012.000548

98. Yabroff KR, Davis WW, Lamont EB, Fahey A, Topor M, Brown ML, et al. Patient time costs associated with cancer care. J Natl Cancer Inst (2007) 99:14-23. doi:10.1093/jnci/djk001

Conflict of Interest Statement: The author declares that the research was conducted in the absence of any commercial or financial relationships that could be construed as a potential conflict of interest.

Received: 02 October 2014; paper pending published: 19 October 2014; accepted: 11 February 2015; published online: 07 April 2015.

Citation: Meier R (2015) Dose-escalated robotic SBRT for stage I-II prostate cancer. Front. Oncol. 5:48. doi: 10.3389/fonc.2015.00048

This article was submitted to Radiation Oncology, a section of the journal Frontiers in Oncology.

Copyright (c) 2015 Meier. This is an open-access article distributed under the terms of the Creative Commons Attribution License (CC BY). The use, distribution or reproduction in other forums is permitted, provided the original author(s) or licensor are credited and that the original publication in this journal is cited, in accordance with accepted academic practice. No use, distribution or reproduction is permitted which does not comply with these terms. 